\title{
KRONIK
}

\section{Nisan 2004 Kıbrıs Referandumunun Ardından}

Doç. Dr. Melek M. Fırat, A.Ü. Siyasal Bilgiler Fakültesi

24 Nisan 2004 tarihinde Kıbrıs'ta gerçekleştirilen ve Annan Planı çerçevesinde sorunun çözümü, yani Kıbrıs'n birleşmesi ve tek devlet olarak $A B$ 'ye girmesi için yapılan referandum, sorunun başlangıcından beri ilk kez adanın Türk ve Rum halkına kendi geleceklerini belirlemeleri fırsatını verdiği için büyük önem taşıyordu. Gerçi bu noktaya Soğuk Savaş sonrası uluslararası konjonktür bir çözzümü dayattı̆̆ı, Yunanistan ve Türkiye'nin dış politikaları Kıbrıs'ta çözümü gerektirdiği için gelinmişti ama, geçmişte olduğu gibi dış güçlerin uzlaşması sonucu bir çözümün zorla benimsetilmesi bu defa söz konusu olmayacak, uzlaşı formülünün adanın iki halkı tarafından da onaylanması istenecekti. Bu açıdan, Kıbrıs'ın iki halkının birlikte ve yanyana yaşamaları konusunda iradelerini ortaya koyacakları 24 Nisan referandumu büyük önem taşıyordu.

24 Nisan referandumu uzun ve yapısal değişimlerle dolu bir sürecin son noktasıydı. Soğuk Savaş'ın sona ermesi ve uluslararası sistemin yeniden yapılanma sürecine girmesiyle birlikte Kıbrıs sorununun parametrelerinde de önemli değişiklikler yaşandı. Soğuk Savaş içinde Türkiye'yle Yunanistan arasında bir sorun olarak kabul edilen ve NATO'nun çıkarları gereği TürkYunan dengesi içinde 1974 statükosuna göz yumulan Kıbrıs'ta artık bir çözümün gerekliliği söz konusuydu. Yeni uluslararası sistemin mimarları olarak $A B D$ ve $A B$, hem Doğu Akdeniz'in istikrarına gereksinim duydukları hem de yeni uluslararası sistemin değerleri çerçevesinde Soğuk Savaş'tan kalan sorunları çözerek siyasi meşruiyetlerini sağlamak istedikleri için Kıbris sorununun çözümü konusunda baskı yapmaya başladılar. AB'nin genişleme süreci bunun için gerekli ortamı sağladı ve 1990'da Kıbrıs Rum Yönetimi'nin tam üyelik başvurusuyla süreç işlemeye başladı.

Türkiye ve Yunanistan'ın, dış politikalanını, Soğuk Savaş sonrası şekillenmeye başlayan uluslararası sistemle uyumlaştırma çabaları bu sürece hız kazandırdı. İlk değişiklik işaretleri Yunanistan'dan geldi: Özellikle 1995'te Andreas Papandreu'nun sağlık nedeniyle başbakanlıktan ayrılmasıyla bu görevi üstlenen Kostas Simitis'in, selefinin ölümüyle 1996'da PASOK liderliğine seçilmesi Yunanistan'ın ulusal çıkar tanımını gözden geçirme sürecini başlattı. Soğuk Savaş boyunca NATO çerçevesinde kalarak temel tehdit algıladığı Türkiye'ye 
karşı dış politikasını belirleyen Yunanistan, artık Ankara merkezli ulusal çıkar belirleme dönemini sona erdirerek, daha geniş bir perspektif kazanma girişimlerinde bulundu. 1981'den beri AB üyesi olan Yunanistan hedeflerini büyütecek, Doğu Avrupa'ya doğru genişleme kararı alan Brüksel'le sorunlarını çözecek ve Balkanlar'da bölgesel güç olarak $\mathrm{AB}$ ile yeni katılan üyeler arasında köprü rolünü üstlenecekti. Bu hedefe ulaşabilmesi için ekonomik sorunlarını aşması, kaynaklarını silahlanmadan yatırıma aktarması gerekiyordu; bunun önkoşulu da Türk tehdidi söylemini terk ederek, Ankara'yla diyalog sürecini açmaktı. Ancak Türk-Yunan ilişkilerine egemen olan elli yıllık gerilimi ikili diyalogla çözmek mümkün değildi. Herşeyden önce Türkiye'nin iç koşulları buna izin vermiyordu. Dolayısıyla Simitis, Brüksel üzerinden Ankara'yla ilişkilerini yumuşatma yoluna gitti. Atina'nın 1987'den beri sürdürdüğü Türkiye'nin $A B$ üyeliğine engel olma politikasını terk ederek Ankara'ya bu süreçte destek verme ve bu yolla Türk-Yunan anlaşmazlıklarını AB-Türkiye ilişkilerinin bir parçası haline getirerek çözme, Yunanistan'ın doğuya kilitlenmiş dar ufkunu batıya çevirme ve genişletme politikasını uygulamaya koydu. Atina'nın bu girişimleri ancak 1999'dan itibaren Ankara'dan karşlık görmeye başladı.

1987'de AB'ye tam üyelik başvurusunda bulunan Türkiye'nin Soğuk Savaş sonrasında yeniden yapılanan uluslararası sisteme uyum süreci daha sancilı oldu. Sözkonusu tarihten itibaren Türk dış politikasının ana hedefi AB üyeliğgi olarak belirlendi ama ülkede devam etmekte olan PKK ile silahlı mücadele ve bundan dolayı Kürt sorununa silah dışı çözümün reddedilmesine üstüste yaşanan ekonomik krizler de eklenince, 1990'lar boyunca hem Ankara-Brüksel ilişkileri zedelendi, hem de Türkiye içinde ülkenin geleceğine yönelik, yani AB üyeliğ̈i/karşıtlığı ekseninde tartışmalar başladı. Dolayısıyla ulusal çıkarını AB üyeliğine endeksleyen Türkiye bir yandan bu söylemi sürdürürken, diğer yandan bu hedefin gerektirdiği adımları atamadı ve bu noktada Kıbrıs sorununu AB ile ilişkilerinde bir koz olarak oynama yoluna gitti: 1995 'te Gümrük Birliği Anlaşması'nı imzalarken Rum Yönetimi'nin $\mathrm{AB}$ ile üyelik müzakerelerini başlatmasına sessiz kaldı, 1997 Lüksemburg Zirvesi'nde aday üyeler arasında yer almayınca da bundan böyle Ege ve Kıbrıs gibi Yunanistan'la yaşanan sorunları AB platformlarında tartışmayacağını söyledi. Yunanistan'ın Türkiye'nin $A B$ üyeliği konusundaki tavrını değiştirmesine yol açan Ankara'nın bu restine karşllı, Atina'yla birlikte Brüksel de politika değişikliğine gitti: 1999 Helsinki Zirvesi'nde Kıbrıs ve Ege sorunlanna sonuç bildirgesinde yer verilerek Türkiye aday ülkeler arasında sayıldı. Böylece, her ne kadar önkoşul olmadıkları söylense de Ankara'nın üyelik sürecinin işleyebilmesinin 2002'ye kadar Kıbrıs, 2004'e kadar da Ege sorunlarının çözümüyle bağlantılandırıldığı ya da bu çözümlerin süreci kolaylaştıracağı 
açıktı. Türkiye'nin 1997'de AB'ye karşı oynadı̆̆ı kozu şimdi Brüksel Ankara'ya karşı ileri sürüyordu. 1999 'da Öcalan'ın yakalanması hem Türkiye'nin Kürt sorununa başka perspektiflerden yaklaşmasının önünü açtı, hem de $\mathrm{AB}$ yolunda adımlar atılmasını sağlayan koşulları yarattı. Bundan böyle Türkiye'nin $\mathrm{AB}$ üyeliğini temel dış politika yönlenmesi olarak gören kesimler harekete geçtiler. İçeride reformlar gerçekleştirilirken 2002'den itibaren de Kıbrıs sorunu öne çıkarılmaya başladı. $3 \mathrm{Kasım} 2002$ genel seçimlerinden sonra AKP'nin tek başına iktidara gelmesi süreci hızlandırdı. İçerideki iktidan sorgulanan AKP, AB üyeliği doğrultusunda atılacak önemli bir adımla sağlayacağı dış politika başarısıyla meşruiyetini sağlamlaştırmak istiyordu. Kıbrıs sorununda ilk kez Türkiye'den farklı sesler çıkmaya ve kemikleşmiş partilerüstü "çözümsüzlük çözümdür" anlayışının terk edilebileceğinin işaretleri verilmeye başladı. AKP hükümetinin Kıbrıs politikasına ilk tepki Türkiye'deki AB karşıtı kesimlerle birlikte KKTC Cumhurbaşkanı'ndan geldi. Bu noktada AKP Hükümeti'nin eli zayıfladı ve Annan Planı üzerinden yapılan yoğun tartışmalar sonucunda Aralık 2002 Kopenhag'da gerekli cesareti gösteremedi. Sonuçta Annan Planı askıda kaldı ve Türkiye beklediği gibi kesinleşmiş bir müzakere tarihi alamadı. Kıbrıs sorunu adeta AKP hükümetinin dış politika değişiminin anahtar konusu haline geldi; Kıbrıs kilidi bir kez açılırsa Türkiye'nin diğer tabu konularına sıra gelecekti ve tüm bunların sonucunda ulusal çıkar tanımının yeniden belirlenmesi ve dış politikanın uluslararası sistemle uyumlaştırılması süreci tamamlanacaktı. Ancak Lahey'de kapanan Kıbrıs kilidinin yeniden açılabilmesi için adada bir değişimin yaşanması gerekiyordu.

Türkiye'de 1990'lar boyunca yaşanan ekonomik ve siyasal krizlerin etkileri KKTC'de de görüldü ve Kıbrıs Rum Yönetimi'nin tüm Kıbrıs adına AB'ye üyelik süreci sorunsuz ilerleme kaydederken, ilk kez Rumlar ve Türkiye dişında bir alternatif üzerine düşünme şansı yakalayan Kıbrıslı Türkler hem Türkiye'yle ekonomik ve siyasal ilişkilerinin yapısı üzerine, hem de kendi ülkelerindeki yapısal bozukluklar hakkında düşünmeye, varolan statükoyu sorgulamaya başladılar. Türkiye-AB ilişkilerinde Kıbrıs sorununu gündemin ilk sırasına oturtma süreci ise KKTC'deki muhalefeti harekete geçirdi. 28 Haziran 2002'de yapılan belediye seçimlerinde Cumhuriyetçi Türk Partisi (CTP) Lefkoşa, Girne ve Moğosa gibi üç büyük kentte belediye başkanlıklarını kazanınca muhalefet gücünün bilincine vardı ve giderek sesini daha fazla duyurmaya başladı. Ocak 2002'den beri süren toplumlararası görüşmelerde Cumhurbaşkanı Denktaş'ın tutumunu eleştirdiği gibi, 10 Kasım 2002'de BM Genel Sekreteri'nin sunduğu Annan Planı çerçevesinde bir çözüme ve $A B$ üyeliğine tam destek verdi. Ancak kitlelerin gösterileri ne Ankara'da duyuldu (duyulduğu kadarıyla da "vatana ihanet" suçlamasıyla karşılandı) ne de Denktaş'ın yaklaşımını etkileyebildi. Bu 
süreç sonunda Kopenhag ve ardından Lahey'de çözüm arayışlan kesintiye uğradı. İlk raunt sona ermişti ama KKTC'deki sol muhalefet için AKP iktidarının Kıbrıs politikası önemli bir destekti. Nitekim, 14 Aralık 2003 seçimlerine gidilirken AKP Hükümeti'nin KKTC'deki seçimlere hiçbir müdahale olmayacağına ilişkin açıklamaları muhalefeti rahatlattı. Seçim propagandalarının ana teması Annan Planı ve AB üyeliğiydi. Katılımın \% 85'e ulaştığı seçim sonuçlarına göre, \% 5'lik barajı aşabilen sol partilerden Cumhuriyetçi Türk Partisi (CTP) \% 35,18, Barı̧ ve Demokrasi Hareketi (BDH) $\%$ 13,14, sağ partilerden de Ulusal Birlik Partisi (UBP) \% 32,30, Demokrat Parti (DP) \% 12,93 oy alarak sirasiyla parlamentoda $19,6,18$ ve 7 sandalye sahibi oldular. Kıbrıs Türk halkı \% 50-\%50 bir ağırlıkla hem Annan Planıve $\mathrm{AB}$ üyeliği konusunda oy vermiş gibi görünüyordu hem de gündemin hareketli olduğu bu dönemde ulusal uzlaşı talebini belirtiyordu. Nitekim, bir sol (CTP) ve bir sağ ( DP) partinin uzlaşmasıyla koalisyon hükümeti kuruldu. CTP lideri ve Başbakan Mehmet Ali Talat sonuç ne olursa olsun görüşmeleri yeniden başlatmak ve ısrarla masada kalmak, yani görüşmeleri ilk terk eden olmamak gerektiğinin altını çiziyor; hatta Denktaş'ın değil, başbakan olarak kendisinin görüşmelerde yer almasının önemini belirtiyordu. KKTC'de ilk kez taşlar yerinden oynamıştı ve bu sonuç AKP hükümetinin elini rahatlatmıştı. İlginç bir biçimde KKTC solu Türkiye'de İslam'a referans yapan sağ bir hükümetle el sıkışıyordu. Bu ise Başbakan Erdoğan'ın Ocak 2004'te Davos'ta BM Genel Sekreteri'yle yaptığı görüşmelerde Türk tarafının her zaman bir adım önde olacağı ve 1 Mayıs 2004'ten önce bir çözüm için elinden gelen çabayı göstereceği sözünü vermesine ve Annan'dan görüşmeleri yeniden başlatmasını istemesine yol açtı. Kıbrıs konusunda 24 Nisan'a varacak ikinci raunt başlamıştı.

Gerek Türkiye, gerekse KKTC'nin olumlu çaba içine girdiği bu ikinci rauntta Kıbrıslı Rumların aynı coşku içinde olduğunu söylemek mümkün değil. Ocak 2002'de Kleridis'in başkanlığında başlayan görüşmelerde $A B$ üyeliği kesinleşmiş değildi ve taraflar iyiniyetli çaba göstermek durumundaydılar. Özellikle Annan Planı masaya getirildiğinde en az Türk tarafı kadar memnuniyetsizlik gösterseler de, Kıbrıslı Rumlar Kopenhag Zirvesi boyunca geleneksel taktiklerini izleyerek ve Türk tarafının masadan kalkmasını bekleyerek süreci tamamladılar. Türk tarafının masadan kalkmasıyla da 13 Aralık 2002'de AB üyeliğini kesinleştirmişlerdi. Bu dönemde tek risk Türk tarafının evet demesiyle Annan Planı ve $A B$ üyeliğinin aynı referandumda oylanmasıydı ve bu risk Türk tarafının tutumu sonucunda bertaraf edilmiş̧i. 16 Şubat 2003'te yapılan seçimlerde EOKA geçmişi bulunan ve AKEL'den destek alan Tasos Papadopoulos'un Cumhurbaşkanı seçilmesi Rum tarafının bundan sonraki tutumunun ne olacağını gösteriyordu: Madem ki $\mathrm{AB}$ üyeliği güvence 
altına alınmıştı, ekonomik olarak çok daha geri olan Türk kesimine para aktarmanın, siyasal olarak tanınan tek devlet olmanın avantajlarından vazgeçmenin ya da bu avantajları paylaşmanın hiçbir getirisi kalmamıştı; o halde neden şimdi Annan Planına evet denilecekti? Kıbrıslı Türklerin çözüm için harekete geçtiği dönemde, Kıbrıslı Rumlar için çözümün cazibesi kalmamıştı. Ancak, dünya kamuoyunun baskısıyla Papadopoulos gönülsüzce de olsa yeniden masaya oturmak zorunda kaldı. EOKA'cr Papadopoulos'un tek umudu TMT'ci Denktaş'ın süreci engellemesiydi ama KKTC ve Türkiye'deki siyasal değişim Denktaş'ın gücünü kırmıştı.

Davos'ta Başbakan Erdoğan'ın girişiminden cesaret alan BM Genel Sekreteri, taraflara yeniden görüşmelere başlamalan için davet mektubu yolladı. 10 Şubat 2004 'te New York'a giden KKTC heyetine yine Denktaş başkanlık yapıyordu ama beraberinde Başbakan Talat ve Başbakan Yardımcısı/Dışişleri Bakanı Serdar Denktaş da gelmişlerdi. Cumhurbaşkanı Denktaş daha New York'a gelmeden bir mektup hazırlamışı ve amacı bu mektubun Genel Sekreter'e verilmesiyle birlikte masadan kalkmaktı. Papadopoulos ise, tıpkı Lahey'de olduğu gibi ilk hareketi Denktaş'tan bekliyordu ve nasıl olsa Türk tarafı süreci kesintiye uğratır beklentisi içindeydi. Ancak, bu beklenti gerçekleşmedi çünkü Türkiye'den New York'a giden Dışişleri Bakanlığı Müsteşarı Uğur Ziyal Ankara'daki siyasi iradenin tüm ağırlığıyla görüşmelere damgasını vurmasını sağladı ve her tıkanıklığ a çacak formülleri üreterek taraflanı masadan kalkmasını önledi.

New York'ta kabul edilen takvime göre, Kıbrıs Türk ve Rum tarafı 19 Şubat'ta Lefkoşa'da görüşmelere başlayacaklardı ve 22 Mart'a dek sürecek görüşmelerde bir uzlaşıya varılamazsa, Türkiye ve Yunanistan'ın da katılacakları dörtlü görüşmeler 29 Mart'a dek yapılacaktı. Bundan sonra hala uzlaşma sağlanamamış noktalar kalırsa BM Genel Sekreteri boşlukları dolduracak ve tarafların itiraz edemeyecekleri nihai metin 21 Nisan'da referanduma sunulacaktı. İlginç bir tabloyla karşı karşıya kalınmıştı: Gerek Denktaş, gerek Papadopoulos New York sonucundan memnun değillerdi ama itiraz edememişlerdi; ilk kez BM Genel Sekreteri'ne geleceğe yönelik tam yetki veriliyor ve son noktayı Kıbrıs halkının koyması sağlanıyordu.

Takvim New York'ta belirlendiği gibi işledi. Kıbrıs'ta başlayan görüşmeler kerhen 22 Mart'a kadar sürdürüldü. Denktaş ve Papadopoulos baskılar karşısında masadan kalkamıyorlardı ama sonuca yönelik bir çaba içinde olduklan da söylenemezdi. İki lider uzlaşmama konusunda uzlaşmışlardı ve Papadopoulos'un eli Denktaş'a göre daha rahattı çünkü 7 Mart'ta Yunanistan'da yapılan seçimler sonucunda PASOK iktidardan ayrılmış ve seçimleri kazanan Yeni Demokrasi Partisi hükümeti kurmuştu. İlk kez başbakanlık koltuğuna oturan Konstantin Karamanlis hernekadar PASOK'un 
Kıbrıs politikasında bir değişiklik yapılmayacağını söylese de Papadopoulos'a baskı yapabilecek tecrübe ve güce henüz sahip değildi. 22 Mart'taki 15 . oturumdan da bir sonuç çıkmayınca ikili görüşmeler sona erdi. İsviçre'nin Burgenstock kasabasında 24 Mart'ta dörtlü görüşmeler başladı. Bir hafta süren görüşmelerden de uzlaşı çıkmadı ve 1 Nisan'da Annan son biçimini verdiği planını taraflara sundu. Artık referandum sürecine geçilmişti.

24 Nisan'a kadar gerek Kıbrıs Türk kesiminde gerekse Kıbrıs Rum kesiminde propaganda süreci başladı. Türk kesiminde kartlar açık oynanıyordu: CTP, $\mathrm{BDH}$ başta olmak üzere sol partiler ve $\mathrm{AB}$ yanlıları plana son haliyle "evet" denmesini isterken, Cumhurbaşkanı Denktaş son kozunu oynayarak, UBP'yle birlikte "hayır" denmesi gerektiğini halka anlatıyorlardı. Tavrı açık olmayan tek parti Serdar Denktaş'ın başkanlığını yaptı̆̆ hükümetin ortağı DP'ydi. Başkan Denktaş parti yetkili kurullarından net bir karar çıkmayınca ve babasının tutumuna da açık tavır alamayınca kendisinin referandumda "hayır" oyu vereceğini ama partilileri oylarında serbest bıraktıklarını açıkladı.

Kıbrıs Rum kesimine gelince, Papadopoulos'un partisi DİKO açık ve kesin bir biçimde hayır kampanyasını yürüttü. Hatta referandum yaklaştıkça, Annan Planı bir tarafa bırakılarak doğrudan milliyetçi duygulara hitap eden bir demagoji atağı başlattı ki buna son noktayı Papadopoulos gözyaşları içinde "Halka Sesleniş" konuşması yaparak koydu. Buna karşın Kleridis’ten boşalan koltuğa oturan Nikos Anastasiadis'in başkanlığını yaptığı sağcı DİSİ partisi "evet" kampanyasını küçük partilerle birlikte yürüttü. Kısa bir süre önce yapılan başkanlık seçiminde DİKO \% 15, DİSİ \% 34 oy almışlardı. DİKO'nun adayı Papadopoulos, ancak AKEL'in desteğiyle oyların \% 55'ini alarak başkan seçilebilmişti. Şimdi, referandum sürecinde de kilit parti komünist AKEL'di. Kıbrıs Türk solunun da umudu, yıllardır paralel çizgide hareket ettiklerine inandıkları AKEL'di. Ancak son ana kadar parti içi tartışmaların devam ettiği, CTP ve BDH liderleri Talat ile Akıncı'nın çeşitli ikna ziyaretinde bulundukları AKEL son kararını "hayır" yönünde vererek gerek Kıbrıs Türk, gerekse Kıbrıs Rum solundaki barış yanhllarını hayal kırıklığına uğrattı. AKEL'in "hayır" gerekçesi DIKO'dan farklı olarak Annan Planı'nın özüne değil, uygulanabileceğine inanmadıklarına dayanıyordu. Uluslararası güçlerin son bir girişimde bulunarak BM Güvenlik Konseyi'nden güvence çıkması doğrultusundaki çabalarına da Rusya Federasyonu veto uygulayınca, meşru gerekçe sağlamış oldular!

24 Nisan referandumu olaysız geçti ve sonuçlar bir sürpriz yaratmadı: Kuzeyde $\%$ 64,9 evet, \% 35,1 hayır çıkarken, güneyde \% 24,2 evet, $\% 75,8$ hayır oyu kullanıldı. Dolayısıyla Kıbrıslı Türkler ezici bir çoğunlukla ortak bir şemsiye devlet altında birarada yaşama, çözüm, barış ve $A B$ üyeliği isteklerini dile getirirken, Kıbrıslı Rumlar yine ezici bir çoğunlukla varolan kendi devletlerine 
sahip çıkma, AB üyeliğinden tek başına yararlanma ve Türklerle yanyana ama birlikte yaşamama konusundaki iradelerini ortaya koymuşlardı. 1974'ten bu yana geçen süreç içinde giderek zenginleşen ve siyasal meşruiyeti tanınan Rumlar statik bir tutumu benimserken, statükonun olumsuzluklarını yaşayan Türkler daha dinamik bir tavır alma cesaretini gösterebilmişlerdi.

24 Nisan'da Kıbrıs'ın iki kesiminde yapılan ve Annan Planı çerçevesinde Kıbrıs Türk ve Rum halkına birlikte yaşamak konusundaki fikirlerinin sorulduğu referandum dar bir bakış açısıyla adadaki sorunun çözümü için yapılmış ve sonuca varmamış onlarca plandan birinin daha sona erdirilmesi olarak değerlendirilebilir. Ancak, kısa vadeli siyasal değerlendirmeler bir yana koyulduğunda, 24 Nisan çok daha önemli ve anlamlı bir tarihi dönemecin kesinleşmiş işaretidir. Geri dönüşü olmayacak bir biçimde Kıbrıs sorununun nitelik değiştirdiğini ortaya koymuştur ve bundan sonra tarafların geleneksel çizgilerini sürdürmeleri mümkün olmayacaktır. Dolayısıyla referandum sürecinden çıkan sonuçları daha ayrıntılı bir değerlendirmeye tabi tutarsak şu noktalara dikkat çekilebileceğini ileri sürebiliriz:

1. Soğuk Savaş mantığı içinde hareket eden ve gerek uluslararası sistemdeki gerekse Kıbrıs'taki değişim sürecinin gerisinde kalan iki lider Denktaş ve Papadopoulos aynı çizgide buluşabilmişler, milliyetçilik ötesi bir bakış geliştiremeyerek el sıkışmışlardır.

2. Papadopoulos'la aynı çizgide yer alan Denktaş, kendi halkının gerisine düşerek liderlik niteliğini kaybetmiştir. Bundan böyle açık bir biçimde Kıbrıslı Türklerin geleceğe yönelik özlemlerini dile getiren liderler olarak Talat ve Akıncı öne çıkmıştır. Bu ise, Kıbrıs sorununun başlangıcından beri bir ilktir.

3. Kıbrıs sorunu Kıbrıslı Türkler açısından nitelik değiştirmiştir çünkü 1990 öncesinde Kıbrıs sorunu Lefkoşa'da da Türkiye'nin bir dış politika sorunu olarak algılanırken, artık Kibrıslı Türkler kendi ayakları üzerinde durarak kendi geleceklerini belirleme isteklerini Ankara'ya göstermişlerdir. Şimdiye dek anavatan/yavru vatan temelinde kurulmuş olan hiyerarşik ilişki artık iki müttefik anavatanın eşitlik temelinde kurulacak ilişkisine dönüşmek durumundadır.

4. KKTC'deki askeri varlığını ulusal güvenliğinin olmazsa olmaz koşulu haline getirmiş olan ve tüm Soğuk Savaş boyunca Kıbrns konusunu "milli dava" olarak kabul edip partilerüstü bir politikayı tek ses olarak dile getiren Türkiye'de de artık Kıbrıs sorunu nitelik değiştirmektedir. Bu sadece Kıbrıs sorununun çözümüne yönelik farklı görüşlerin dile getirilebilmesi gibi basit bir değişim değildir. Bunun çok ötesinde Türk dış politikasının geleceğinin ve ulusal çıkarın yeniden belirlenmesi sürecinin başlangıcıdır. $A B$ 
bağlamında yapılan ve Kıbrıs'a uzanan Türk dıs politikasının geleceği üzerine tartışmalar aynı zamanda Türkiye'nin yeniden yapılanması sürecini de içinde barındırmaktadır ve sadece hükümet ile bürokrasi arasında değil, her kurum içinde tartışmalar ve görüş farklılıkları dile getirilmektedir. Kıbrıs gibi tabu bir konunun tartışılabilmesi, Türkiye'nin artık sadece Kıbrıs değil, Ermeni, Kürt vb. tabularını yıkabileceğinin de bir işaretidir ve bu, yeni uluslararası sistemle uyumlu dış politikanın ilk adımıdır.

5. Kıbrıs Rum Yönetimi'ne gelince, her ne kadar Papadopoulos dahil "hayır" çağrısı yapan tüm liderler çözüme değil, Annan Planı'na "hayır" dediklerini vurgulasalar da, Kıbris Rumlannın \% 75 gibi büyük bir oranı geleceğe değil, geçmişe bağlılıklarını ortaya koydular. Böylece, sadece Türk kesiminin uzattığı zeytin dalını reddetmekle kalmayıp, üyesi oldukları AB değerlerini de benimsemediklerini gösterdiler. Reel politika temelinde konuştuğumuzda ise, Kıbrıs Rum Yönetimi hem içinde yer alacağı AB ile sorunlu ilişkilere başlıyordu, hem de ilk kez en az Türk tarafı kadar uzlaşmaz olduğunu, milliyetçiliğin dar perspektifinden geleceğini belirlemeye devam edeceğini dünya kamuoyuna bu denli açık bir biçimde bildiriyordu.

6. Kıbrıs Rum solu, bir başka ifadeyle AKEL bu süreçten en başarısız çıkan parti oldu. Geçmişte olduğu gibi bugün de kendi ideoloji ve politikalarını dile getirme cesareti gösteremeyen AKEL, milliyetçilerin peşine takılarak kendi kimliğine ihanet etti. Bununla da kalmadı, yıllardır vatana ihanet suçlamalarına gögüus gererek barış ve iki halkın birlikte bir gelecek oluşturması çabasını gösteren Kıbrıs Türk soluna da ihanet etti. Kendi desteğiyle başkan seçilen Papadopoulos'u zorlayabilecek tek parti iken, Dimitris Hristofias EOKA'cı Papadopoulos'un çizgisine geçti. Tıpkı bugün geçmişteki politikalarının hesabını vermekte zorlandığı gibi, gelecekte de bugün izlediği politikaların hesabını vermekte zorlanacağı muhakkaktır. Emperyalizmin dayattığı bir planının reddedilmesi biçimindeki bir açıklama ne Kıbrıs Türk solunu ne de dünya solunu tatmin edecektir.

7. Referandum sonucundan sonra uluslararası toplumun Kıbris sorununa bakışı da değişim geçirmek durumunda kalacaktır. Şimdiye dek, Kıbrıs Türk liderliğinin tutumundan da kaynaklanan nedenlerle Türk kesimini cezalandırma temelinde bir politika izleyen büyük devletler ve uluslararası örgütler 24 Nisan'da bildikleri ama bilmemezlikten gelmeyi tercih ettikleri bir gerçekle karşı karşıya kaldılar. Başta $\mathrm{AB}$ olmak üzere tüm uluslararası örgütler ve büyük devletler eğer yeni uluslararası sistemin temelinin uzlaşma, hoşgörü, çok kültürlü yaşama dayalı demokrasi ve hukukun üstünlüğü olduğu iddialarının arkasında duracaklarsa Kıbrıs sorununa ve 
özellikle KKTC'ye yönelik politikalarını gözden geçirmek durumundadırlar.

Tüm bu noktaları göz önünde tutuğumuzda, söylenebilecek belki de tek sonuç 24 Nisan referandumundan sonra gerek Kıbrıs'ta, gerek Türkiye'de hiçbir şeyin eskisi gibi olamayacağıdır. Taşlar bir kez yerinden oynamıştır ve özeleştiri süreci başlamıştır. Umut edilen, bundan böyle Türk dış politikasının tabu konularını tartışmaya açarak, salt güç ve stratejik önem üzerinden politika yürütme alışkanlığını aşabilmesi ve Kıbrıs sorununa çözüm sürecinde görüldüğu gibi Dışişleri Bakanlığı'nın başarılı kadrolarını kullanarak diplomasi ve hukuk temelli bir dış politika yürütebilmesi, "dört tarafı düşmanlarla çevrili" Türkiye söyleminin yerini "komşularıyla iyi ilişkiler içinde bulunan, kendisiyle ve dünyayla barışı" Türkiye söylemine bırakmasıdır. Dış politikadaki bu değişimin iç politikaya yansımalarının sonuçlanı, yeni uluslararası sisteme eklemlenme çabası içindeki egemen sintfların, yani hiçbir şey değiştirmeden "herşeyi değiştirenler"in çizdikleri sınırın çok ötesine geçebilecek potansiyeller de taşımaktadır. 